\title{
Lissencephaly type 3-metacarpal bone dysplasia syndrome
}

INSERM

\section{Source}

INSERM. (1999). Orphanet: an online rare disease and orphan drug data base.

Lissencephaly type 3-metacarpal bone dysplasia syndrome. ORPHA:86822

This syndrome is characterised by severe microcephaly, agyria, agenesis of the corpus callosum, cerebellar hypoplasia, facial dysmorphology and epiphyseal stippling of the metacarpal bones. It has been described in two brothers. The syndrome is transmitted as an autosomal recessive trait and may be an allelic variant of $\mathrm{Neu}$-Laxova syndrome and Lissencephaly type III with cystic dilations of the cerebellum and foetal akinesia sequence (see these terms). 